archway leaning towards the left, i.e. having its highest point to the left of the middle point of its base. As before stated, the flap almost blocks up the tunnel, so that to get to the nectar-holes the proboscis must pass over the top of the flap, and must therefore travel along the highest part of the tunnel, but since at the entrance arch the highest point is to the left, the bee finds it necessary to go to the left of the coiled-up carina to reach the nectarholes in the easiest way. If this view of the function of th: fl $\mathrm{p}$, when considered in relation with the disposition of the pisii, carina, \&c., be correci, it adds another instance to the long list of mechanisms for ensuring the cross-fertilisation of flowers by means of the visits of insects.

FRANCIS DARWIN

\section{THE FRENCH MUUSEUM OF PHYSICAL AND MECHANICAL SCIENCE}

MHE following official report of General Morin, the 1 director of the Conservatoire des Arts-et-Métiers, Paris, to the Minister of Agriculture and Commerce, which we take from the fournal of the Society of Arts, furnishes some interesting details as to the present condition of this magnificent educational establishment, the like of which, dealing as it does with experimental and mechanical science, is entirely wanting in our country, although in the British Museum, the student of Natural History finds all he needs.

"The total number of persons who attended the lectures of the fourteen professors amounted in 1872 to $\mathrm{I} 35,443$, at 559 lectures, or in the proportion of 24I to each lecture. The smallest number of lessons given by any one professor was 40 , from the opening in the commencement of November, until the last days of April. The total number of persons attending is smaller than in preceding years, which is explained by the decrease of the floating population of Paris. This year, as in all others, the decrease commenced when the days got longer, and work kept the people in the workshop.

"I would here limit this report if I did not think it necessary to add a few words upon the means of instruction which the Conservatoire offers to the public and the working-classes of ali ranks.

"This establishment, as is known, owes its origin to the illustrious Vaucanson, inspector of factories, who, aiter having made at the Hotel du Montagne, Rue de Charonne, a collection of machines, instruments and tools, for the instruction of workmen, presented it to the Government, on the sole condition that its original purpose should be maintained. Louis XVI. accepted the gift by an act of council, and the illustrious Vandermonde, member of the Academy of Sciences, was named administrator and conservator of this first industrial museum. Later, by the decrees of the 15 th and 18 th of August, 1'793, the Convention created a temporary commission of arts, to pat a stop to the dispersion of objects of art, science, and industry. This commission succeeded in collecting a large number in a depot formed at the Hotel d'Aiquillon, Rue de l'Université. The value of these collections soon after determined the Convention, upon the report of Gregory, to make a decree, the 19 Vendémaire, year 3 , that there should be formed in Paris, under the name of Conservatoire des Arts-et-Métiers, a public collection of machines, models, tools, drawings, descriptions, and books of all kinds of arts and science, the use of which should be explained by three lecturers attached to the establishment.

"It may be well to mention that the title of 'demonstrateur' or lecturer, often corresponded to that of professor, and that the professors of the Jardin des Plantes remained long after they had commenced giving regular courses. However that may be, the organisation of the Conservatoire, which was checked by several circum- stances, was again mooted by Alquier at the Council of the Ancients, on the 27th Nivose, year 7 , which urged the great advantage of such an institution to workmen, by saying that it is of more use showing them articles than merely s eaking of them. It was not, however, until the 12th Germinal, year 7, that the buildings of the priory of St. Nicholas of the Fields were put into the possession of the members of the Conservatoire, who were then composed of Le Roy, Conti, Molard, and Benvelot, designer. The names of these savants, and that of Montgolfier, who soon after replaced Le Roy, did not allow of any comparison being made betwee $n$ the functions of these lecturers and those who are differently named now-a-days.

"At length, in the year 8 , all the models and machines belonging to the State were definitively removed to this building, and formed collections destined solely for the instruction at sight. The functions implied by the title of lecturer were never exercised, and this will easily be believed when it is said that the numerous visitors who are attracted by the rich collections sometimes amount to 200,000 , which makes all verbal explanation on the spot impossible. But that which is not possible to do for the public has been for a long time afforded by the Conservatoire to persons who are really desirous of information. A complete and methodical catalogue has been made out and published, and to it are added, from time to time, all new acquisitions; this has already passed through four editions. The galleries have been systematically classified, a guide has been placed in each, who, if he cannot give any practical explanation, can at least show where such and such a model is to be found, each of which is ticketed and numbered, both in the catalogue and in the inventory. Should an engineer or a workman wish to examine separately a machine or machinery, a study card for the necessary time is given to him. Or should any more complete information or explanation be required, either the curator of the collections, the under-director, or the director, is always ready to furnish them, their office being freely open to all.

"The staff in charge of the collections consists of the conservator, an assistant conservator, and of fourteen chosen guardians, who, for the most part, are picked from old non-commissioned officers or soldiers. The wish to give explanations by these, even with the aid of written details for the 9,000 models or articles which are there, would lead to great errors and confusion by a zealous but a badly instructed staff. In asking that popular conferences such as are held at the Polytechnic Institution of London, should be introduced here, account has not been taken of the great difficulties which stand in the way, and greatly exaggerated ideas exist as to their value.

"It is not by common and vulgar explanations that the principles of Science can be spread amongst our workmen, and the facts and experience which are so necessary; their minds and intelligence are developed enough, so no fear need be had to speak to them on difficult scientific questions, if it is done with wisdom.

"All the professors who have followed this mode of teaching have often been convinced, on meeting some of their old hearers in workshops, that what may be termed the knowledge of truth and scientific principle has more deeply entered into their minds than into that of scholars of more celebrated schools. Hence it was not without reason that, in 1819 , a decree of the king, brought about by the respected Dean, $M$. le Baron Charles Dupin, added to the instructions at sight given by the collections, that of oral instruction in the amphitheatres, by professors chosen from among the ranks of science. The number of chairs, at first only three, is now fourteen, and the half of the professors are members of the Institute, who diffuse and popularise science, the progress of which they promote by their labours. This instruction, unique of its kind in Europe, only takes place during winter; it is free 
to all without any condition for admission or any examination, and the number of persons who have frequented it during the last few years amounts to from 150,000 to I 80,000 .

"To the honour of workmen it must be said, that a more attentive audience can nowhere be found; never does the slightest disorder arise, and I am happy to say that during the unhappy events which have taken place in France, the Conservatoire was always respected, and underwent no disturbance or invasion.

"But if we think the part of casual lecturers in the galleries useless, and if we are convinced that the real duty of the Conservatoire des-Arts-ei-Métiers consists in the classification, maintenance and increase of its collections, and in the teaching of the applied sciences, which it gives on such a large scale, we also believe that the Government should attach great importance to that teaching, which, during twenty years, we have developed under the name of technical education, and which has produced such good results in several of our great industrial centres.

"Your department pursues the realisation of this wish, and we hope it will be able, with the aid of the resources placed at its disposil by the National Assembly, to develop more and more this practical instruction, which, beginning at the primary school, gradually enables men, according to their intelligence and love of study, to rise from the lowest to the highest grades of society."

\section{NOTES}

We have with much regret to record the death of Mr. Edward Blyth, on December 27 last, in his sixty-fourth year. Of Mr. Blyth it may be said that he was a Zoologist in the truest sense of the word, and his practical knowledge of the birds and manmals of India and the surrounding countries was probably greater than that of any living naturalist. Up till 1840 he devoted himself to the stuay of the ornithology of the British Isles, and in that year appeared an English translation of Cuvier's "Regne Animale," in which the mammals, birds, and reptiles were edited by him; many of bis own notes suggesting modifications in the then existing systems of classification, lave been subsequently fully substantiated and adopted. For twenty-two years after tinis date Mr. Blyth held the post of Curator to the Calcutia Museum of the Asiatic Society of Bengal, during which time, and in conjunction with Dr. Jerdon, he did more than anyone to advance the study of Natural History in India, and to improve the value of the collection he controlled. After a short visit to Burmah, during which he did much good to zoological work, he returned to England in 1863 , since which time he has contributed many valuable papers to onithological and other journals, and tinder the very appropriate signature "Zopplinus," a large number of excelient articles to the Fiel $\dot{u}$. With an unparalleled memory $\mathrm{Mr}$. Blyth combined exceptional powers of observation and a genuine enthusiasm for natural history, which is but rarely seen; these made his imprometu observations and opinions of more than ordinary value, and no one was more willing than himself freely to give all information at his command, towards the assistance of any fellow. worker, or the elucidation of any difficulty in his favourite subject.

Dr. Francis C. WebB, editor of the Medical Times and Gazette, died suddenly on the morning of December 24 last, at the age of 47 years.

AT a preliminary meeting of the Varley Testimonial Committee, held on November $2 \mathrm{O}$, it was resolved to recommend that a Memoir of the Iate Cornelius Varley, illustrated with a Photographic Portrait, should be prepared and issued under the superintendence of the Committee, and that a copy be pre. sented to his family, in token of the high estimation in which he was held; and further, that some Memorial be erected to his memory at the place of his interment.

TELEGRAMs from Naples of the 3 rd and 4 th inst, state that Prof. Palmieri announces a severe eruption of Vesuvius to be imminent. A rumbling noise is audible from the mountain, and although fire has not been seen in the interior of the craters, the density of the smoke indicates the proximity of fiery matter.

Mr. MANley Hopkins, Consul-General at Hawaii, having written to the Times that he had discovered in the Samoan Islands a living specimen of the Dodo, believed to have been extinct a century ago, Prof. $O$ wren wrote to the same paper that the bird referred to is the dodlet. "The extinct dodo of the Island of Mauritius was about six times bulkier. Coloured figures of both birds-that of the dodo, copied from paintings by the Dutch artists, who saw the living bird in the time of their Stadtholder Maurice, that of the dodlet from the bird living in the Zoological Gardens about ten years ago, with the skeletons of both didus and didunculus are given in my work on the Dodo (quarto)."

A VERY suggestive anatomical point has been made out by Sir Victor Brooke, respecting the tarsus in certain of the Cervidle. He finds that in the species of the genus Cervutus (the Muntjacs), the tarsus, instead of consisting of a naviculo-cuboid bone, together with two separate cuneiform bones, has the outer of the two cuneiform masses anchylosed to the naviculo-cuboid mass, to form a single bone, leaving the minute internal cuneiform free. In a very young specimen of Cervulus muntjac the cuboid was free, and the naviculare anchylosed to the outer cuneiform bones, showing that the tendency to blend in this direction is greater than that of the naviculare and the cuboid to combine. This same peculiarity is also found in the Pudu Deer of South America.

THE question as to the limit of capability of the microscope is investigated by Prof. Abbe, of Jena, in a recent number of Max. Schultze's Archiv; and he is led by a series of physical deductions to the remarkable result, that this limit is already as good as reached by our best microscopes, and that all hope of a deeper penetration into the material constitution of things, than such microscopes now afford, must be dismissed. Experiment and theory agree in showing how the changes wrought by diffraction of light passing through fine structures, whose elements are so small and near each other as to call forth this phenomenon, are such as to prevent the object being imaged more geonsetrico. Thus it may happen, on the one hand, that different structures give the same microscopical image, and, on the other, that like structures give different images. Consequently, while objects of the kind (systems of fine lines and the like) may appear ever so distinct and well marked in the microscope, we are not entitled to regard such appearances as of morphological significance, but merely as physical phenomena, from which nothing further can certainly be inferred than the presence of such structural conditions as are capable of producing the diffraction effects obtained. The remark has notable applications to many of the microscopical researches on markings of diatoms, and on striated muscular fibre. And it affects not merely the morphological relations of the objects, but the deductions, made from microscopical observation, as to properties (such as differences of transparence, colours, polarisation, \&c.). The author lays down the following principle as basis for determination of a limit :By no microscope can parts be distinguished (or the marks (Merkmale) of a really present structure perceived), if they are so near to each other that the first bundle of light rays produced by diffraction can no longer enter the objective simultaneously with the undiffracted cone of light. Prof. Abbe has also recently described a new illuminating apparatus for the microscope, 